\title{
Comparative and functional genomic analyses of the pathogenicity of phytopathogen Xanthomonas campestris pv. campestris
}

\begin{abstract}
Wei Qian, ${ }^{1,9}$ Yantao Jia, ${ }^{1,9}$ Shuang-Xi Ren, ${ }^{2,3,9}$ Yong-Qiang He, ${ }^{4,9}$ Jia-Xun Feng, ${ }^{4,9}$ Ling-Feng Lu, ${ }^{2,9}$ Qihong Sun, ${ }^{1}$ Ge Ying, ${ }^{1}$ Dong-Jie Tang, ${ }^{4}$ Hua Tang, ${ }^{5}$ Wei Wu, ${ }^{1}$ Pei Hao, ${ }^{6,7}$ Lifeng Wang, ${ }^{1}$ Bo-Le Jiang, ${ }^{4}$ Shenyan Zeng, ${ }^{1}$ Wen-Yi Gu, ${ }^{2}$ Gang Lu, ${ }^{2}$ Li Rong, ${ }^{8}$ Yingchuan Tian, ${ }^{1}$ Zhijian Yao, ${ }^{8}$ Gang Fu, ${ }^{2}$ Baoshan Chen, ${ }^{4}$ Rongxiang Fang, ${ }^{1}$ Boqin Qiang, ${ }^{8}$ Zhu Chen, ${ }^{2}$ Guo-Ping Zhao, ${ }^{2,3,7,10}$ Ji-Liang Tang, ${ }^{4,10}$ and Chaozu He ${ }^{1,10}$
\end{abstract}

${ }^{1}$ National Key Laboratory of Plant Genomics, Institute of Microbiology, Chinese Academy of Sciences, Beijing 100080, P. R. China; ${ }^{2}$ Laboratory of Health and Disease Genomics, Chinese National Human Genome Center at Shanghai, Shanghai 201203, P. R. China; ${ }^{3}$ National Key Laboratory of Genetic Engineering/Department of Microbiology, School of Life Science, Fudan University, Shanghai 200433, P. R. China; ${ }^{4}$ Guangxi Key Laboratory of Subtropical Bioresources Conservation and Utilization, Guangxi University, Nanning 530004, Guangxi, P. R. China; ${ }^{5}$ Department of Ecology and Evolution, University of Chicago, Chicago, Illinois 60637, USA; ${ }^{6}$ Shanghai Center for Bioinformation Technology, Shanghai 200235, P. R. China; ${ }^{7}$ Bioinformation Center/Institute of Plant Physiology, Shanghai Institutes for Biological Sciences, Chinese Academy of Sciences, Shanghai 200032, P. R. China; ${ }^{8}$ Chinese National Human Genome Center at Beijing, Beijing 100176, P. R. China

\begin{abstract}
Xanthomonas campestris pathovar campestris $(X c c)$ is the causative agent of crucifer black rot disease, which causes severe losses in agricultural yield world-wide. This bacterium is a model organism for studying plant-bacteria interactions. We sequenced the complete genome of Xcc 8004 (5,148,708 bp), which is highly conserved relative to that of Xcc ATCC 33913. Comparative genomics analysis indicated that, in addition to a significant genomic-scale rearrangement cross the replication axis between two IS1478 elements, loss and acquisition of blocks of genes, rather than point mutations, constitute the main genetic variation between the two Xcc strains. Screening of a high-density transposon insertional mutant library $(16,512$ clones) of Xcc 8004 against a host plant (Brassica oleraceae) identified 75 nonredundant, single-copy insertions in protein-coding sequences (CDSs) and intergenic regions. In addition to known virulence factors, full virulence was found to require several additional metabolic pathways and regulatory systems, such as fatty acid degradation, type IV secretion system, cell signaling, and amino acids and nucleotide metabolism. Among the identified pathogenicity-related genes, three of unknown function were found in Xcc 8004-specific chromosomal segments, revealing a direct correlation between genomic dynamics and Xcc virulence. The present combination of comparative and functional genomic analyses provides valuable information about the genetic basis of Xcc pathogenicity, which may offer novel insight toward the development of efficient methods for prevention of this important plant disease.
\end{abstract}

[Supplemental material is available online at www.genome.org. The sequence data of Xcc 8004 from this study have been submitted to GenBank under accession no. CP000050.]

Xanthomonas campestris is a gram-negative, pathogenic bacterium that belongs to the $\gamma$-subdivision of Proteobacteria. It was genetically differentiated into over 141 pathovars (pv.), each with a specific host range (Dye et al. 1980; Swings and Civerolo 1993). The variant $X$. campestris pv. campestris (Xcc) generally invades and multiplies in cruciferous plant vascular tissues, re-

\footnotetext{
${ }^{9}$ These authors contributed equally to this work.

${ }^{10}$ Corresponding authors.

E-mail hecz@im.ac.cn; fax 86-10-62548243.

E-mail gpzhao@sibs.ac.cn; fax 86-21-64837495.

E-mail jltang@gxu.edu.cn; fax 86-771-3237873.

Article and publication date are at http://www.genome.org/cgi/doi/10.1101/ gr.3378705. Article published online before print in May 2005.
}

sulting in the characteristic "black rot" symptoms of blackened veins and $\mathrm{V}$-shaped necrotic lesions at the foliar margin (Alvarez 2000). Xcc invades into plant tissues through hydathodes, stomates, roots, or wounds, and infects a wide range of plants in the crucifer family (Brassicaceae), including broccoli, cabbage, cauliflower, radish, and the model plant Arabidopsis thaliana. Thus, this bacterium represents a problematic bacterial pathogen. Periodic epidemics of black rot disease have occurred world-wide, especially in the developing regions of Africa and Asia, where high temperatures and humidity can aggravate the damage (Swings and Civerolo 1993). Each epidemic can cause substantial yield loss in agricultural production. However, an efficient, lowpollutive control treatment has not, as of yet, been developed (Swings and Civerolo 1993). 
The recent rapid development of genomics has brought a paradigm shift to bacterial pathogenesis research (Wren 2000). Although the complete genomic sequence of Xcc ATCC 33913 (da Silva et al. 2002) provided a profile of genetic information to explore $X c c^{\prime}$ s biological characteristics, the functions of about one-third of the protein-coding sequences (CDSs) are yet to be assigned, and a large repertoire of genes, including virulence determinants, have not been experimentally defined. Thorough annotations using comparative and functional genomic technologies are essential for gaining a systematic understanding of the biology of black rot disease and for facilitating the development of better preventive techniques.

We choose Xcc 8004 and its susceptible host plant cabbage (Brassica oleraceae) as the pathosystem for the present study. Xcc 8004 is a spontaneous rifampicin-resistant strain derived from Xcc NCPPB No. 1145 (isolated from infected cauliflower, B. oleracea var. botrytis, in Sussex, UK, 1958). It is a genetically amendable strain widely used for phytopathological studies, such as studies of secretion of extracellular enzymes and exopolysaccharides (Tang et al. 1991; Wilson et al. 1998), cell-cell signaling (Slater et al. 2000), and biofilm formation (Dow et al. 2003). Xcc ATCC 33913 was isolated from cabbage (B. oleracea var. gemmifera) and its genome served as a reference for comparison. Although Xcc ATCC 33913 and Xcc 8004 cause similar necrogenic symptoms, these two strains differ in their growth rate on minimal medium and in their host range in the five commercial cruciferous plants (Table 1). In particular, Xcc ATCC 33913 exhibited weak or little virulence against the tested cultivars (cv) of cabbage (B. oleracea cv. Jingfeng 1) and radish (Raphanus sativus cv. Huaye).

We sequenced and annotated the complete genome of Xcc 8004, and compared it with that of Xcc ATCC 33913 (da Silva et al. 2002). Subsequently, we screened an Xcc 8004 transposon insertional mutant library with $4 \times$ genomic coverage (Sun et al. 2003) against its host plant $B$. oleraceae for pathogenicitydeficient mutants, from which 75 genes with diverse functions were identified, including previously undefined genes and three strain-specific genes of unknown function. This screening is one of the largest in scale for either animal or plant bacterial pathogens (Kavermann et al. 2003; Kurz et al. 2003; Bae et al. 2004).

\section{Results}

\section{General genomic features}

The Xcc 8004 genome resides on a single circular chromosome $(5,148,708$ bp, Fig. 1.) with a $\mathrm{G}+\mathrm{C}$ content of $64.94 \%$, which is larger than that of the Xcc ATCC 33913 (5,076,187 bp, Table 2). Like Xcc ATCC 33913 (da Silva et al. 2002), Xcc 8004 was found not to have a plasmid. The replication origin of the Xcc 8004 genome was predicted to be at the intergenic region of $d n a A$ and dnaN by GC-skew analysis and a similarity search. Approximately $63 \%$ of the CDSs (2671) were assigned to biological functions (Table 2). Thirty-two phage-related genes, including two copies of $\phi L f$ filamentous phages that specifically infect Xcc (Lin et al. 1996), were identified in the genome. In addition, there were 115 insertion sequence elements, ranging from 0.8 to $1.6 \mathrm{~kb}$ and belonging to 15 groups, distributed throughout the genome. The 4273 predicted CDSs in the Xcc 8004 genome are depicted in Supplemental Figure 1.

\section{Comparative genomics}

A high degree of gene content conservation was observed between the genomes of Xcc 8004 and Xcc ATCC 33913. The majority of the CDSs (3467) found in Xcc 8004 are identical to those in Xcc ATCC 33913, not only at the amino-acid level, but also at the nucleic-acid sequence level. However, single-nucleotide polymorphisms (SNPs) were detected in 498 CDSs with identical gene length, which account for about $12 \%$ of the total CDSs. In order to assess the effect of nonsynonymous mutations upon the intraspecies differentiation of the two strains, we analyzed the ratios of total nonsynonymous SNPs vs. total synonymous SNPs (A/S) of these 498 genes in four functional categories regarding pathogenicity ([I] normal physiology, [II] unknown functions, [III] virulence factors, and [IV] pathogenicity-related, Table 3). The A/S ratio for pathogenicity-associated genes (category III and IV) did not differ significantly from that of the other groups (Table 3). Therefore, the overall intensity of the selection force for the genes among the different groups was very similar. In other words, pathogenicity-associated genes did not show any significant bias in response to selection compared with the other

Table 1. Pathogenicity properties of wild-type strains of Xanthomonas campestris pv. campestris and the Xcc 8004 strain-specific mutants tested on various host plants

\begin{tabular}{|c|c|c|c|c|c|}
\hline & \multicolumn{5}{|c|}{ Average virulence level (standard deviation) ${ }^{a}$} \\
\hline & Cabbage & $\begin{array}{l}\text { Radish } \\
\text { (Huaye) }\end{array}$ & $\begin{array}{c}\text { Radish } \\
\text { (Xiaojingzhong) }\end{array}$ & $\begin{array}{l}\text { Chinese } \\
\text { cabbage }\end{array}$ & $\begin{array}{l}\text { Pakchoi } \\
\text { cabbage }\end{array}$ \\
\hline \multicolumn{6}{|l|}{ Wild-type strains } \\
\hline Xсc 8004 & $4(0.00)$ & $4(0.00)$ & $4(0.00)$ & $4(0.00)$ & $4(0.00)$ \\
\hline XсC ATCC 33913 & $0.67(0.49)^{\mathrm{b}}$ & $0(0.00)$ & $4(0.00)$ & $3.7(0.49)^{\mathrm{b}}$ & $4(0.00)$ \\
\hline \multicolumn{6}{|c|}{ Xcc 8004 strain-specific segment mutants } \\
\hline XC2055 & $1.9(0.20)^{\mathrm{b}}$ & $4(0.00)$ & $4(0.00)$ & $1.9(0.20)^{\mathrm{b}}$ & $2.9(0.20)^{\mathrm{b}}$ \\
\hline XC2068 & $1.8(0.39)^{b}$ & $2.3(0.65)^{\mathrm{b}}$ & $3.3(0.87)^{b}$ & $3.8(0.62)$ & $3.8(0.45)$ \\
\hline XC2416 & $2.0(0.14)^{b}$ & $0.3(0.49)^{\mathrm{b}}$ & $3.8(0.39)$ & $2.9(0.52)^{b}$ & $4(0.00)$ \\
\hline Control & 0 & 0 & 0 & 0 & 0 \\
\hline
\end{tabular}

${ }^{a}$ Virulence level scale and plant inoculation approach are described in Methods (Dow et al. 1990). Each average virulence level was calculated from a data set consisting of $\geq 36$ inoculation sites distributed over $\geq 3$ leaves on $\geq 6$ individual plants. Symptoms were scored on the 10th day post-inoculation. Standard deviations are shown in the parentheses.

b $P<0.05$ vs. Xcc 8004 , by $t$-test. 


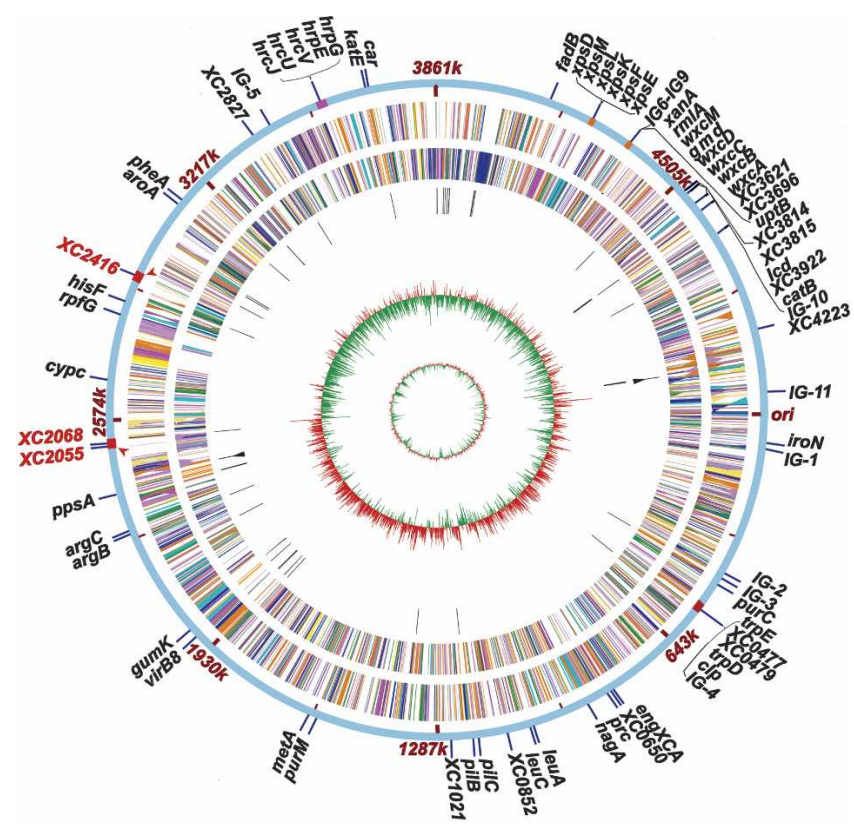

Figure 1. Circular representation of the $X c c 8004$ genome and $E Z:: T N$ transposon insertion sites of virulence-reduced mutants. Circles range from 1 (outer circle) to 7 (inner circle). (Circle 1) EZ::TN insertional locations, gene names, or codes are according to Supplemental Table 3; (IG) intergenic region; ori, the origin of DNA replication; Red arrowheads indicate Xcc 8004 strain-specific chromosomal segments. (Circle 2) CDSs on forward strand. (Circle 3) CDSs on reverse strand. (Circle 4) tRNA genes. (Circle 5) rRNA genes. (Circle 6) GC skew $[(\mathrm{G}-\mathrm{C}) /(\mathrm{G}+\mathrm{C})]$, red indicates values $>0$ and green $<0$. (Circle 7 ) $\mathrm{G}+\mathrm{C}$ contents. Colors in circle 2 and 3 represent functional categories; orange for intermediary metabolism; green for biosynthesis of small molecules; blue for macromolecule metabolism; magenta for cell structure; khaki for cellular processes; green for biosynthesis of small molecules; light-blue for mobile genetic elements; pink for pathogenicity, virulence, and adaptation; yellow for hypothetical and conserved hypothetical proteins; dark-green for ORFs with an undefined category.

functional groups. However, the exact contribution of point mutation in phenotypic difference between the two strains can only be determined by examining the functional role of each alteration.

In addition to the SNP mutations noted, insertion/deletion and related variations were observed in 200 pairs of genes (Table 2). We also identified 108 and 62 CDSs unique to Xcc 8004 and Xcc ATCC 33913, respectively (Supplemental Table 1). The majority of these genes were localized to strain-specific chromosomal segments (Fig. 2).

Segment M $(60 \mathrm{~kb})$ and $\mathrm{N}(58 \mathrm{~kb})$ are unique to Xcc 8004 . Segment M possesses 44 CDSs. Within segment $M$ are genes relevant to plasmid mobilization, recombination (e.g., integrase and DNA helicase), and cellular regulation, such as those encoding hemolysin activation protein (XC2404), ankyrin repeat protein (XC2428), and a chaperone-like ATPase (XC2433) with $\mathrm{AAA}^{+}$ domain, as well as 28 genes of unknown function. The $\mathrm{G}+\mathrm{C}$ content value at the synonymously variable third position (GC3s) of segment $\mathrm{M}$ is $0.580 \pm 0.091$, which is lower than that of the whole Xcc 8004 genome $(0.801 \pm 0.081)$. In addition, the codon usage of genes within this segment is distinctly biased from the whole genome (Supplemental Table 2). Therefore, segment $\mathrm{M}$ was likely to be acquired via horizontal gene transfer. Although most of the 52 CDSs in segment $\mathrm{N}$ encode hypothetical proteins, 39 of them have orthologs (BLASTP search, $e<10^{-5}$ ) in the genome of a closely related species, $X$. axonopodis pv. citri (Xac) strain 306 (da Silva et al. 2002). A deletion event may have occurred in the genome of Xcc ATCC 33913 during its evolution, which eventually made this segment unique in Xcc 8004.

Segments D (18 kb) and G (37 kb) are Xcc ATCC 33913 specific (Fig. 2). Segment D contains seven genes, with gene products that include an oxidoreductase, a DNA methylase, and two DNA helicases. Segment G possesses 51 CDSs, which includes genes encoding two polymerase $\mathrm{V}$ subunits and a site-specific DNA-methyltransferase. Because most of the genes in this segment are phage related, it likely originated from phage integration.

The majority of the genes encoded by the two genomes were identical, and the nonsynonymous variations are unlikely to be the main driving force of evolution (see above). Thus, the identified strain-specific genes might contribute to the biological differences between the two Xcc strains. It is worth emphasizing that among the $X c c 8004$ strain-specific genes, there are two type IV secretary pathway related genes (XC2031 and XC2040), and both of them possess TraG/TraD and ATPase domains. Findings with the gastric pathogen Helicobacter pylori (Israel et al. 2001) and the plant crown gall disease pathogen Agrobacterium tumefaciens (Cascales and Christie 2003) suggested that proteins of this kind are putative NTPases functioning as coupling factors to facilitate communication between a transport pore and its substrate molecules. In addition, Xcc 8004 contains several strainspecific genes that encode proteins with putative transport functions, including a transport transmembrane protein (XC2405), an arsenite efflux pump (resistant to arsenic toxicity, XC2294), and a high-affinity $\mathrm{Fe}^{2+} / \mathrm{Pb}^{2+}$ permease (pumping out heavy metals, XC2295).

\section{Genomic colinearity}

Comparison of Xcc (strains 8004 and ATCC 33913) and Xac (strain 306) genomes revealed a dramatic pattern of genomic rearrangement (Fig. 2). In contrast to the considerable colinearity between the genomes of Xcc ATCC 33913 and Xac, significant rearrangements, including translocation, inversion, and insertion/deletion, were clearly recognized between the genomes of Xcc 8004 and Xcc ATCC 33913. These findings are consistent with the view that Xac and Xcc ATCC 33913 may represent the prototypes of these xanthmonads, while Xcc 8004 may have originated via recent recombination events. By comparing the pattern of genomic organization, one may notice that except for the DNA segments flanking the replication origin (segments A, B, and L, Fig. 2), the segments of the two Xcc genomes are located symmetrically at mirror-image positions across the replication axis. This significant rearrangement may have resulted from a single round of homologous recombination. There are two identical IS1478-related genes (Xcc0535 and Xcc3627) present at each extreme end of the predicted recombination site (on the end of segments L and B) on the Xcc ATCC 33913 genome. They may be the preferred sites for homologous recombination during replication (Tillier and Collins 2000). Segments I and K are also translocated across the replication axis, but they are inverted in their orientations relative to the other segments, which indicates that more than one round of recombination events occurred on them. A mechanism of this putative genomic rearrangement process is thus deduced and shown in Supplemental Figure 2 as a detailed, animated depiction. 


\section{Screen for virulence-reduced mutants}

Using a highly efficient transposon-based mutagenesis system, we previously constructed a Xcc 8004 random insertional mutant library that covers the genome approximately four times (Sun et al. 2003). A total of 16,512 transformants were screened individually on the susceptible host plant cabbage (B. oleracae cv. Jingfeng 1) and 172 pathogenicity-deficient mutants were obtained. The virulence capacities of these mutants were confirmed by at least six rounds of independent inoculation experiments, with no less than 36 inoculation sites per mutant (see Methods). These multiple replications and numerous sites enabled growth phase variation and stochastic factors to be excluded. Among the pathogenicity-related mutations, 75 nonredundant, single-copy transposon insertional disrupted CDSs or intergenic regions were identified by Southern blotting and flanking sequence analysis, and then mapped to the Xcc 8004 genome (Fig. 1, the outermost circle). Although transposon insertion may cause polarity on downstream genes within an operon and thereby complicate the subsequent genetic analysis, these mutants remain informative, as most of the operons comprise functionally related genes.

These mutated genes were assigned to diverse functional categories (Fig. 3; details in Supplemental Table 3). In addition to 25 previously defined virulence genes, such as $h r p G, c l p, r p f G$, and gumK, 39 new genes and 11 intergenic regions were identified, providing insight into the genetic basis of Xcc pathogenicity (Fig. 3; details in Supplemental Table 3).

The distribution of insertions in the library was assessed previously by identifying both the genomic location and the functional distribution of 50 randomly chosen clones (Sun et al. 2003; this study). Three annotated pathogenicity-related genes (virB8, $r b f C$, and $b f e A$ ) were identified from these 50 candidates. This ratio $(6 \%)$ was consistent with the overall expected ratio (250 annotated pathogenesis-related genes of a total of $\sim 4200$ genes, about $5.9 \%$ ), and it is worth noting that virB8 was also identified from the later mutant-screening process. We further assessed the distribution of the mutant library by comparing the ratio of the number of genes identified by this mutagenesis ex-

Table 3. Comparison of SNP frequency and distribution of CDSs between Xcc 8004 and Xcc ATCC 33913

\begin{tabular}{|c|c|c|c|c|c|c|c|c|c|}
\hline Groups $^{a}$ & $\begin{array}{l}\text { No. } \\
\text { CDS }\end{array}$ & $\begin{array}{l}\text { Total } \\
\text { SNPs }^{\text {b }}\end{array}$ & A & $S$ & $\begin{array}{c}\text { Average } \\
\text { SNP/codon } \\
\left(10^{-3}\right)\end{array}$ & $A / S$ & $P_{I}^{c}$ & $P_{I I}$ & $P_{I I I}$ \\
\hline I & 269 & 1734 & 381 & 1353 & 1.656 & 0.282 & & & \\
\hline II & 163 & 1345 & 315 & 1030 & 2.739 & 0.306 & 0.3633 & & \\
\hline III & 47 & 284 & 71 & 213 & 1.522 & 0.333 & 0.2902 & 0.6226 & \\
\hline IV & 19 & 185 & 39 & 146 & 1.439 & 0.267 & 0.8531 & 0.5390 & 0.3857 \\
\hline Sum & 498 & 3548 & 806 & 2742 & 1.915 & 0.294 & & & \\
\hline
\end{tabular}

${ }^{\text {a }}$ Groups defined as (I) genes not involved in pathogenicity; (II) genes with undefined category and unknown-function; (III) genes whose products are virulence factors that interacted directly with host plant cells; (IV) gene that interacted indirectly with host cells, but is required for full bacterial virulence.

b(SNPs) single-nucleotide polymorphisms; (A) number of nonsynonymous SNPs; (S) number of synonymous SNPs; (average SNP/codon) ratios of total SNPs vs. total number of codons; (A/S) ratios of total nonsynonymous SNPs vs. total synonymous SNPs.

${ }^{c} P$-values from $\chi^{2}$ test for the difference in $A / S$ ratios in all the pairwise comparisons among the four functional groups. periment for each functional category related to pathogenicity ferent functional categories. Most mutations were identified genes related to cell-surface component biosynthesis, enzymeems. The extremely low frequencies (even zero) of certain subroups are interesting topics for further discussion. On the other nicity/virulence were found in relatively low frequencies $(<10 \%)$. Mutations of genes involved in fatty-acid degradation $(15.4 \%)$ thons to this trend. In addition to the relatively low coverage of the library $(4 \times)$, one likely cause of the above-mentioned bias may have allowed for the selection of only those mutations that cause significant decreases of pathogenicity. The 75 nonredundant genes identified here under such selection criteria would be expected to be nontrivial for pathogenicity. However, extrapolations of these mutagenesis results require caution, with respect to the coverage and distribution bias issues of the analysis.

\section{Surface structure and appendages}

Infection is initiated with bacterial attachment to and colonization of host tissues via surface structures and appendages. Specifically, type IV pili may contribute to bacterial pathogenesis by affecting adhesion, twitching mobility on a solid surface, and secretion or interac-

\section{Genome Research}

www.genome.org 


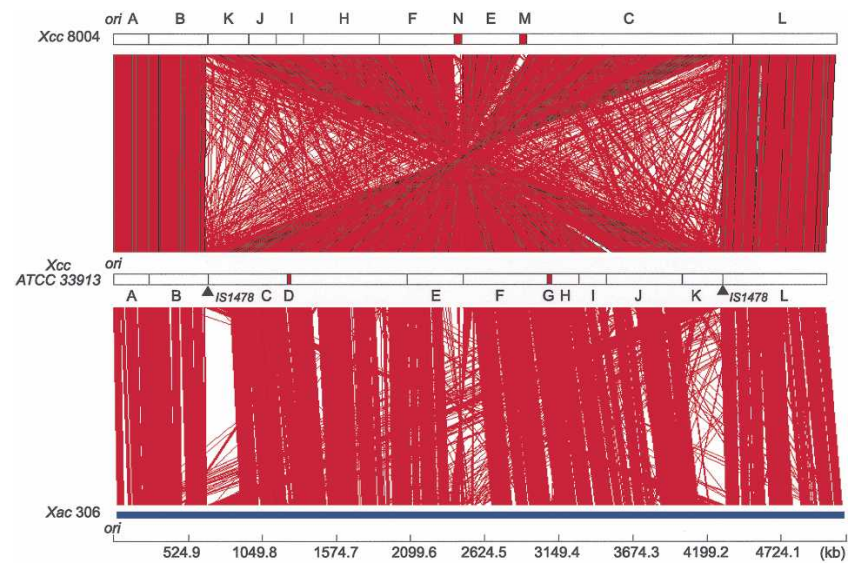

Figure 2. Linear genomic comparison of Xanthomonas campestris pv. campestris (Xcc) 8004, Xcc ATCC 33913, and X. axonopodis pv. citri (Xac 306). The red lines represent similar DNA sequences (BLASTN search, $e$-value $<10^{-5}$ ) between genomes. A-N designate the chromosomal segments, with strain-specific segments (D and G in XcC ATCC 33913 and $\mathrm{M}$ and $\mathrm{N}$ in Xcc 8004) colored red. Black triangles indicate IS1478, the preferred recombination sites for genomic scale rearrangement. (ori) The origin of DNA replication. Genomic sequences of XcC ATCC 33913 and Xac 306 are according to da Silva et al. (2002).

tion with host tissues (Craig et al. 2004). Genomic annotation revealed that at least 26 genes are related to type IV pili assembly and are highly conserved in Xcc 8004 and Xcc ATCC 33913 genomes. Mutations were identified in two of these pili assembly genes, pilB and pilC, which encode multidomain proteins driving energy-prone polymerization of pilin (Supplemental Table 3).

The majority component of the exopolysaccharides (EPSs) secreted by Xcc is xanthan gum, an anionic cellulosic (1-4) $\beta$-Dglucose polymer with trisaccharide side chains. EPS was demonstrated to be a virulence determinant in Xcc. They may mask the bacterium to prevent host recognition and enable colonization of host tissues (Alvarez 2000). The biosynthesis pathways of xanthan gum have been studied extensively (Becker et al. 1998). From the 16 annotated EPS biosynthesis-related genes (Table 4; Supplemental Table 3), we obtained three mutants, $r m l A$, xanA, and gumK, responsible for the biosynthesis of L-rhamnose, glucose/mannose 1-phosphate, and glucuronic acid- $\beta$-1,2-mannoseCel-P-P-lipid, intermediates for xanthan formation, respectively (Becker et al. 1998).

Lipopolysaccharides (LPSs), also known as endotoxins, are a group of well-documented virulence determinates for animal pathogens (Lerouge and Vanderleyden 2002). Although LPS was less studied in phytopathogenic bacteria, it might play a wide range of roles during Xcc infection (Newman et al. 2002). We identified 10 mutants related to LPS biosynthesis (Table 4; Supplemental Table 3) with various biological functions, such as synthesis of O-antigen $(w x c A, w x c B, w x c C$, and $w x c D)$, LPS core (gmd) and N-acetyl-3amino hexose ( $w x c M)$ (Vorholter et al. 2001).

Two mutations were localized to a 5.2-kb gene cluster within chromosome segment $\mathrm{C}$, which consists of three poorly characterized genes. XC3815 was annotated in the genome of Xcc ATCC 33913 and is thought to encode a conserved hypothetical protein (da Silva et al. 2002). However, its nonpathogenic mutant displayed small rough colonies, and further domain analysis indicated that it likely encodes an O-antigen polymerase. In contrast, the nonpathogenic mutant of XC3814, presumably encoding LPS core biosynthesis glycosyl transferase, forms normal colo- nies. Although there was no mutation found in XC3813, it was annotated as a gene encoding glycerophosphotransferase by domain analysis. The position of the XC3813-XC3815 gene cluster relative to the $w x c$ gene cluster differs between Xcc ATCC 33913 and Xcc 8004. In Xcc ATCC 33913, the XC3813-3815 and wxc gene clusters are on opposite sides of the replication origin (oriC) (Vorholter et al. 2001), whereas in Xcc 8004, these two gene clusters are located on the same side of the oriC, and the XC38133815 cluster is $190 \mathrm{~kb}$ downstream of the $w x c$ cluster.

In addition to the eight mutations mentioned above, three independent intergenic insertions (IG7 IG9, Supplemental Table 3) were identified upstream of the function-unknown XC3605 gene. This gene encodes a putative protein with an RgpF domain that is commonly found in rhamnose synthesis proteins. It thus might be related to rhamnose-glucose polysaccharide assembly and is eventually associated with O-antigen biosynthesis (Shibata et al. 2002).

The other identified mutant, nagA, which encodes $\mathrm{N}$-acetylglucosamine-6-phosphate deacetylase, was associated with reduced virulence. It may catalyze the hydrolysis of the N-acetyl group of N-acetylglucosamine-6-P to yield glucosamine 6-phosphate and acetate, and therefore is also involved in cell-surface structure formation. It is interesting to note that nagA is associated with virulence in the animal mucosal pathogen Candida albicans (Kumar et al. 2000)

\section{Detoxification}

Once bacteria have successfully invaded host tissues, hostdefensive chemicals and an oxidative burst are the major hurdles to be overcome (Van Sluys et al. 2002). The Xcc 8004 genome encodes nine glutathione S-transferase (GST), two glutathione peroxidase, and four catalases to detoxify these chemicals. In addition to mutations in genes encoding catalases ( $k a t E$ and $c a t B$ ) that may detoxify reactive oxygen species (ROS) during plant defensive processes, we found a mutant of $u p t B$, which encodes maleylacetoacetate isomerase, an unusual $\zeta$-class of GST that catalyzes the isomerization of $\mathrm{C}=\mathrm{C}$ double bond in ringcleavage products of aromatic compounds (Vuilleumier and Pagni 2002). This enzyme is likely to be associated with the inactivation of xenobiotic chemicals.

Unlike the xylem-limited phytopathogen Xylella fastidiosa (Simpson et al. 2000), Xcc genomes contain intact metabolic pathways for fatty acid oxidation. One mutated gene $(f a d B)$ encodes a p-hydroxycinnamoyl CoA hydratase/lyase, which catalyzes the hydration of 2-trans-enoyl-CoA into 3-hydroxyacyl$\mathrm{CoA}$, the second step in fatty acid $\beta$-oxidation. Another mutated gene $(c y p C)$ encodes fatty acid $\alpha$ hydroxylase, which contains a cytochrome P450-like domain and catalyzes the initial reaction in $\alpha$-oxidation of fatty acid in the presence of $\mathrm{H}_{2} \mathrm{O}_{2}$ (Matsunaga et al. 1997). Mutations in lipid degradation genes leading to attenuation of virulence have been reported previously for animal pathogens, such as Mycobacterium tuberculosis and Salmonella typhimurium (Mahan et al. 1995). It may be that these pathways provide a protective mechanism for Xcc cells by degrading host toxic fatty acids, or alternatively, they may affect basic cellular activities in a manner that reduces in fitness.

\section{Secretion systems}

Both animal and plant pathogenic bacteria use secretion systems (SSs) to deliver extracellular enzymes and effectors to host cells. As revealed by whole-genomic sequences, Xcc is 


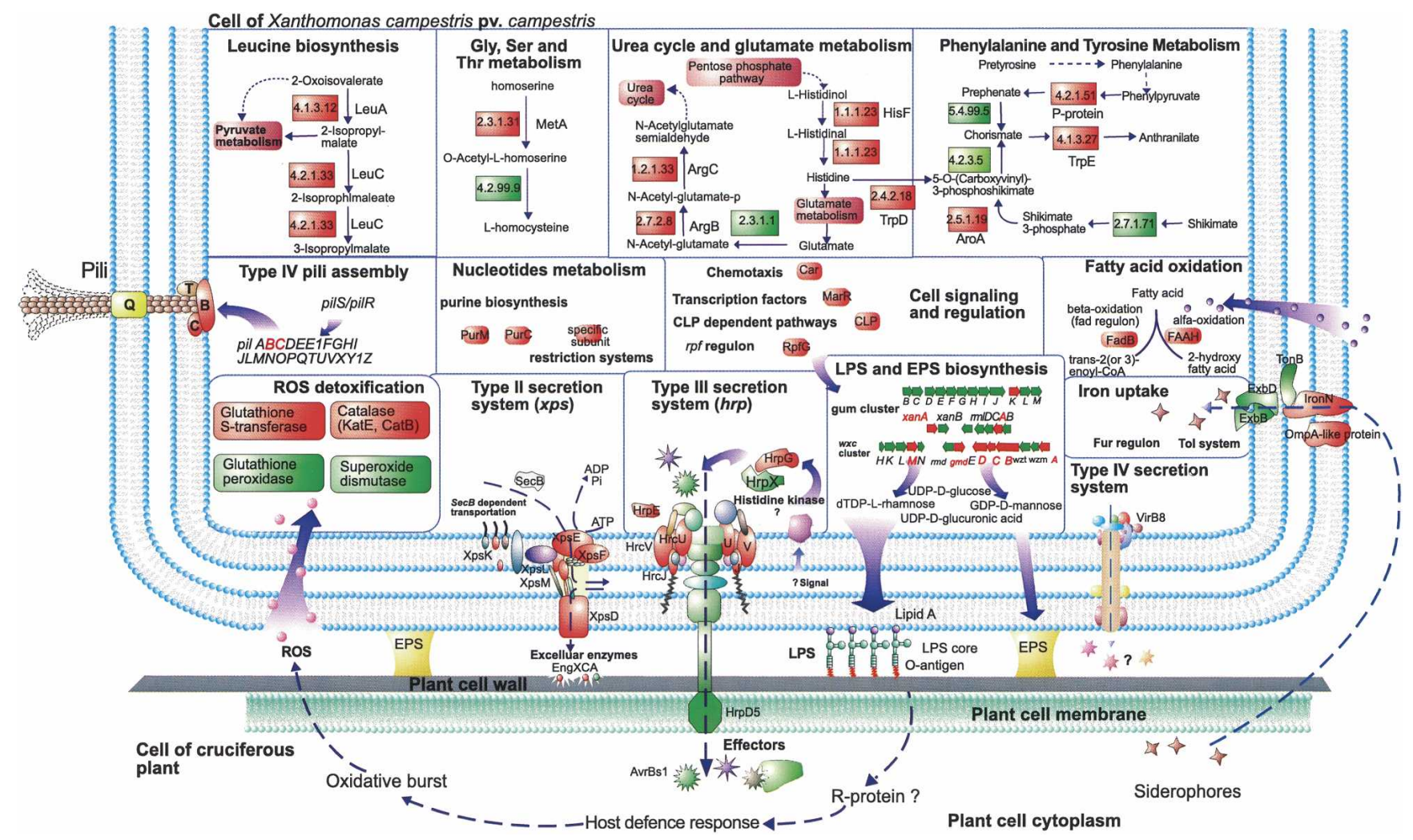

Figure 3. A schematic illustration of the experimentally determined interaction between $X c c$ and host cell. The principle pathways are shown in bold. Putative metabolic pathways were predicted by KEGG. Bacterial genes and gene products associated with pathogenicity are arranged within colored frames. Genes identified in this study are framed in red, while genes that were reported previously in xanthomonads are framed in green. (EPS) Exopolysaccharides; (FAAH) fatty acid $\alpha$ hydroxylase; (Hrp) hypersensitive response and pathogenicity genes; (LPS) lipopolysaccharides; (ROS) reactive oxygen species; (R-protein) resistance gene protein; (Xps) Xanthomonas protein secretion.

equipped with two sets of type II SS ( $x p s$ and $x c s$ ). From 11 annotated genes related to the xps system, six pathogenicitydeficient mutants ( $x p s D, x p s E, x p s F, x p s K, x p s L$, and $x p s M)$ and an additional gene (engXca, encoding exocellular cellulase) were identified. However, no pathogenicity-deficient mutants were found among the 12 annotated genes related to the xcs system (Table 4). The significant difference in mutant identification rates of these two similar systems, even in light of the insufficient coverage and the biased distribution of the library, suggests that the $x c s$ system may not play an essential role in Xcc pathogenesis.

Type III SS has been studied extensively in X. campestris pv. vesicatoria, the causative agent of bacterial spot in pepper and tomato (Buttner and Bonas 2003). Four mutants of genes encoding type III SS machinery ( $h r c J, h r c U$, $h r c V$, and $h r p E$ ) and one encoding a regulatory protein $(h r p G)$, were associated with complete loss of virulence. Type IV SSs secrete macromolecules such as single-strand DNA in A. tumefaciens and pertussis toxin in Bordetella pertussis (Christie and Vogel 2000), respectively. We identified a mutated gene encoding the channel-forming protein VirB8, and thus, experimentally confirmed the prediction that type IV SS contributes to Xcc virulence (da Silva et al. 2002; Van Sluys et al. 2002).

\section{Cellular metabolism}

To cope with the iron-scarce environment of host tissues, Xcc evolved sophisticated iron transport systems, including the
TonB-ExbB-ExbD, Tol-uptake system, ferric-uptake regulation protein (Fur), and at least 79 TonB-dependent outer-membrane ferric complex receptors. We identified mutants related to four TonB-dependent receptor genes that may participate in the uptake of iron-chelating compounds (siderophores) across the bacterial outer membrane, i.e., iroN, XC4223, and two intergenic mutations (IG3 and IG5, which inserted at the upstream regions of $b f e A$ and $b t u B$, respectively). XC4223 encodes an outermembrane protein that contains complex domain structures, including TonB-dependent receptor, S-layer protein, collagenbinding, and hemaglutinin domains. The mutant of this gene totally eliminated $X c c$ virulence. However, IroN, BfeA, and ButB only contain a single TonB-dependent receptor domain and their mutants only showed reduced virulence. The variability in protein structure associated with virulence suggests that there are likely subtle functional differentiations among TonB-dependent receptors.

Many mutated genes are involved in general metabolism, including those that participate in the shikimate-chorismate pathway (aroA, pheA), leucine (leuA, leuC), histidine (hisF), arginine $(\arg B, \arg C)$, methionine $(m e t A)$, and tryptophan $(\operatorname{trpD}, \operatorname{trp} E)$ biosynthesis, purine de novo biosynthesis (purC and purD) and gluconeogenesis ( $p p s A)$. Except for $p p s A$, these mutants are all auxotrophic as determined by no growth on MMX minimal medium, and thus, they might not reduce pathogenicity phenotype directly, but rather, may simply affect survival due to auxotrophy.

\section{Genome Research www.genome.org}


Table 4. A summary of pathogenicity-related genes and mutants identified in this study ${ }^{\mathrm{a}}$

\begin{tabular}{|c|c|c|c|}
\hline Functional category & $\begin{array}{l}\text { No. genes } \\
\text { annotated in } \\
\text { the genome }\end{array}$ & $\begin{array}{l}\text { No. genes } \\
\text { identified } \\
\text { from mutants }\end{array}$ & $\begin{array}{l}\text { Ratio of genes } \\
\text { identified vs. } \\
\text { annotated }\end{array}$ \\
\hline \multicolumn{4}{|l|}{ Cell mobility } \\
\hline Type IV pili assembly & 26 & 2 & 0.077 \\
\hline Flagellar assembly & 33 & 0 & 0 \\
\hline \multicolumn{4}{|c|}{ Surface polysaccharides biosynthesis } \\
\hline Exopolysaccharides & 16 & 3 & 0.188 \\
\hline Lipopolysaccharides & 57 & 10 & 0.158 \\
\hline \multicolumn{4}{|c|}{$\begin{array}{l}\text { Cell-wall degradation enzymes and } \\
\text { secretion system (SS) }\end{array}$} \\
\hline Type II SS (xps system) & 11 & 6 & 0.545 \\
\hline Type II SS ( $x$ cS system) & 12 & 0 & \\
\hline Cellulase & 9 & 1 & 0.111 \\
\hline Other extracellular enzymes & 15 & 0 & 0 \\
\hline \multicolumn{4}{|l|}{ Effectors and secretion system } \\
\hline Type III SS & 26 & 5 & 0.192 \\
\hline Effectors & 8 & 0 & 0 \\
\hline \multicolumn{4}{|l|}{ Other secretion systems } \\
\hline Type IV SS & 17 & 1 & 0.059 \\
\hline Autotransporters & 5 & 0 & 0 \\
\hline \multicolumn{4}{|l|}{ Detoxification and adaptation } \\
\hline Glutathione S-transferase & 9 & 1 & 0.111 \\
\hline Catalase & 4 & 2 & 0.500 \\
\hline Glutathione peroxidase & 4 & 0 & 0 \\
\hline Fatty acid degradation & 13 & 2 & 0.154 \\
\hline Chemotaxis & 46 & 1 & 0.022 \\
\hline \multicolumn{4}{|l|}{ Related general metabolisms } \\
\hline TonB-dependent receptor & 79 & $4^{\mathrm{b}}$ & 0.051 \\
\hline Amino acid biosynthesis & 115 & 10 & 0.087 \\
\hline Purine biosynthesis & 22 & $3^{b}$ & 0.136 \\
\hline DNA restriction & 18 & 1 & 0.056 \\
\hline Energy metabolism & 210 & $2^{\mathrm{b}}$ & 0.014 \\
\hline Regulatory element & ND & 5 & ND \\
\hline Others ${ }^{c}$ & ND & 16 & ND \\
\hline Total & & 75 & \\
\hline
\end{tabular}

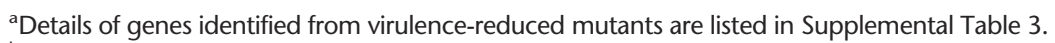

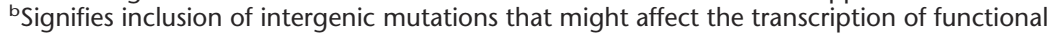
genes.

'This category contains function-unknown genes (including Xcc 8004 strain-specific genes) and part of the intergenic mutations.

\section{Cell signaling}

Several regulatory and responsive genes were found to affect pathogenicity. In addition to the previously reported gene $c l p$ (de Crecy-Lagard et al. 1990), we identified a gene (car) that encodes a transducer car-like protein that may act as a chemosensor for arginine chemotaxis, as reported in Halobacterium salinarum (Storch et al. 1999). The XC2827 gene encodes a putative marR family transcriptional factor and possesses a helix-turn-helix domain. Insertion in XC2827 erased Xcc pathogenicity. A tailspecific protease mutant ( $p r c$ ) also had decreased pathogenicity. This protease was predicted to locate within the periplasmic space (PSORT certainty $=0.928$ ) and contains a PDZ domain that may degrade proteins with a nonpolar $\mathrm{C}$ terminus and solicit cell signaling (Walsh et al. 2003). Although the Xcc 8004 genome encodes 106 two-component signal transduction genes, we identified only two previously reported response regulators ( $h r p G$ and $r p f G)$.

\section{Function-unknown and strain-specific genes}

We obtained mutations in nine genes encoding functionunknown proteins (Table 4) that are involved in the pathogenicity of black rot disease. The presence of recognizable domains, such as helix-turn-helix (XC1021) and haemolysin-type calcium-binding domains (XC3922) in several of the gene products provides hints for further biochemical analysis.

In particular, three mutations that resulted in reduced virulence in cabbage were found to be located in two Xcc 8004-specific segments (Fig. 1; Table 1). The first gene, XC2068, does not have any recognizable domains, but its product has a significant degree of homology ( $e$-value of BLASTP $<10^{-5}$ ) with proteins found in diverse pathogenic bacteria, including Pseudomonas putida, Ralstonia metallidurans, Xylella fastidiosa, Burkholderia fungorum, and Yersinia pseudotuberculosis, suggesting that it may be a virulence determinant in these bacteria. The second, XC2055, was matched significantly with two hypothetical proteins (BPP0494 and BPP0499) of the human pathogen Bordetella bronchiseptica (Parkhill et al. 2003). This protein contains a cell-signaling-related PadR domain, which suggests that it may be a transcriptional factor. The third, XC2416, encodes a hypothetical protein with a $\mathrm{PH}$ domain that has been associated with cell signaling. We inoculated five commercially available crucifers (Table 1) with these mutants and found that their host specificity was different from that of the wild-type strain $X c c$ 8004. These findings suggest that these proteins may be involved in host-specific pathogenesis, and highlight the direct correlation between genomic dynamics and virulence.

\section{Discussion}

The comparative genomics analysis was initiated by studying phylogenetically distant organisms; intraspecies comparison of multiple strains is becoming one of the new trends for studying bacterial pathogens (Whittam and Bumbaugh 2002). It can systematically reveal the genetic variations in genome organization, gene complement, and genetic message expression among different bacterial strains. Such an approach will not only provide insight into the molecular nature of virulence and host specificity, but will also advance our understanding of the evolutionary dynamics responsible for the emergence of novel infectious diseases.

\section{Genomic variation between Xcc 8004 and Xcc ATCC 33913}

We sequenced the complete genome of Xcc 8004 and compared it with that of Xcc ATCC 33913. Our results revealed that the two genomes are highly conserved with respect to gene content. The majority of the CDSs (3467) are actually identical at the nucleicacid sequence level. Although 3548 SNPs are detected in 498 pairs of genes, we did not find any significant bias in mean response to selection force among four major different functional groups for those genes with SNPs, and thus, no strong evidence of relaxation of purifying selection or adaptive evolution for pathogenicity-associated genes was observed.

Large-scale genome reorganization, including deletion or acquisition of blocks of DNA segment and chromosomal rearrangements, were identified in both strains. One of the most 
significant findings in this study is that of a dramatic genome rearrangement that occurred across the replication axis between two Xcc genomes (Fig. 2; Supplemental Fig. 2). This intraspecies event was greater in scale than the interspecies chromosomal rearrangements between Xac 306 and Xcc ATCC 33913. Such a rearrangement pattern, which results in an explicit X-shaped pattern by whole-genomic alignment, has been observed previously between distantly related species, such as between $H$. pylori and Chlamydia jejuni, Vibrio cholera and Escherichia coli, and M. tuberculosis and M. leprae (Eisen et al. 2000; Tillier and Collins 2000). An intraspecies rearrangement of this type was reported previously in a Gram-positive bacterium (Streptococcus pyogenes). In that case, the rearrangement probably occurred at homologous 5.6-kb-long sequences that included 16S RNA, tRNAs, 23S rRNA, and comX1 homologs (Nakagawa et al. 2003). However, the present case is the first of its type recognized in such closely related strains in Xanthomonas. We prefer the replication-directed translocation mechanism (Tillier and Collins 2000) over the wholegenome inverted duplication (Eisen et al. 2000) and alternative transposition (Gray 2000) mechanisms to explain the X-shaped genomic rearrangement in $X c c$, particularly in light of the recognition of two identical copies of IS1478 elements in Xcc ATCC 33913. The two IS1478 elements are located symmetrically at each extreme end of the rearrangement sites with two palindromic sequences immediately upstream (CGGCCCCACG CATGGGGCCG, 837 bp upstream of XCC0535 and GCAGAAG GTCCGACGGACCTTCTGC, 882 upstream of XCC3627). This configuration could form DNA hairpins and might facilitate the initiation of RecA-mediated homologous recombination during replication by cleavage with nuclease and introduction of DNA breaks, as suggested in E. coli (Leach et al. 1997).

There has been a long-standing and unsolved debate regarding the evolutionary impact of large-scale genomic rearrangements upon the global regulation of gene-expression patterns, which may affect the bacterial fitness or result in phenotypic difference, so that the altered bacteria could escape the attack from a host-immune system (Hughes 2000; Feil 2004). Recently, experimental evidences have accumulated to indicate that largescale rearrangements could play a positive role during bacterial adaptation. Such rearrangements were found to be associated with strain diversification in Pseudomonas aeruginosa causing cystic fibrosis (Kresse et al. 2003), resource specialization in E. coli (Zhong et al. 2004), and biofilm formation/antibiotic resistance in Staphylococcus epidermidis (Kozitskaya et al. 2004). Because none of these rearrangements in the two Xcc strains directly broke up any predicted CDS or similar sets of genes, these events may reflect an early state in genome differentiation without obvious phenotypic alterations.

Under these circumstances, strain-specific genomic segments and strain-specific genes therein (insertion and deletion), which may or may not be associated with the large-scale rearrangement process, are of particular interest. As far as Xcc ATCC 33913 was concerned, the majority of strain-specific CDSs in its chromosomal segment $\mathrm{G}$ are phage related (Supplemental Table 1). In addition, although four of seven strain-specific CDSs located on the small Xcc ATCC 33913 segment D do encode an oxidoreductase, a DNA methylase, and two DNA helicases; no direct relationship with pathogenesis can be inferred. On the other hand, pathogenicity-related genes are found in Xcc 8004 strain-specific segments, especially those related to transportation. Later in our mutagenesis experiment, we further identified three genes that encode function-unknown proteins clearly es- sential for full virulence. Collectively, these results indicate that the genetic variation between two Xcc genomes represents a flexible set of "accessory genes" in closely related strains, but with a conserved "core" genome maintained in a species as the backbone (Mushegian and Koonin 1996). This pattern of genetic variation might contribute to rapid development of novel host specificity in pathogenic bacteria by altering virulent ability or cellular viability. Several studies of pathogenic bacteria, such as Helicobacter pylori (Alm et al. 1999), P. aeruginosa (Wolfgang et al. 2003), Staphylococcus aureus (Holden et al. 2004) and X. fatidiosa (Bhattacharyya et al. 2002) are consistent with this possibility.

\section{Identification of black rot disease genes with mutagenesis approach}

Transposon-based, large-scale mutagenesis approaches have been considered to be more efficient than gene expression-based techniques for high-throughput functional analysis (Winzeler et al. 1999; Geoffroy et al. 2003). These mutagenesis approaches were used to identify virulence factors in several pathogenic bacteria, including H. pylori (Kavermann et al. 2003), Stahylococcus aureus (Bae et al. 2004), and Serratia marcescens (Kurz et al. 2003); we reported here for the first time, using this approach to identify Xcc genes essential for black rot disease at the genomic scale.

Because of the relatively low library coverage, the strict screening standards, the specialized inoculation strategy, and the pathosystem used, a certain bias was observed in our data (Table 4). However, when comparing our results with genomic annotations, where about 250 genes in the $X c c$ genomes were predicted to be involved in pathogenicity (da Silva et al. 2002; this study), most of the expected pathways, such as EPS and LPS biosynthesis and detoxifying cascades, were identified by our approach, and data within each of these groups are much less biased than the general data set. Furthermore, we identified a cluster of genes that originally either had no functional assignment or are involved in unpredicted cellular pathways (e.g., fatty acids degradation, cell signaling, and general metabolism) and correlated them to the pathogenesis of the black rot disease. Our results suggest that the mutagenesis approach is advantageous for comprehensive investigation of bacterial pathogenesis.

Based on the available experimental results, we have proposed a molecular genetics model of the essential pathways in Xcc pathogenesis (Fig. 3). Xcc uses various degradative and regulatory mechanisms to parasitize its host, and most of the identified gene's functions are related to surface compounds or secreted compounds (Chan and Goodwin 1999; Alvarez 2000). For example, the $r p f$ gene cluster ( $r p f \mathrm{~A}-\mathrm{I}$, for regulation of pathogenicity factors) positively regulates synthesis of extracellular enzymes, EPS or xanthan (Tang et al. 1991; Slater et al. 2000) and an adipose diffusible signal factor that is related to biofilm dispersal (Dow et al. 2003; Wang et al. 2004).

The novel virulence determinants identified in this study have opened a new avenue to further explore Xcc pathogenesis. For example, although the primary metabolic functions of most metabolic genes have been well studied with respect to normal bacterial physiology, little is known about the relationship between de novo nutrient biosynthesis and pathogenicity (Smith 1998). The present and previous results together indicate that many metabolic genes are involved in bacterial pathogenesis. For instance, purine biosynthesis pathways were identified in rela-

\section{Genome Research}

www.genome.org 
tion to pathogenesis in this study, as well as studies of Brucella abortus (Alcantara et al. 2004), H. pylori (Kavermann et al. 2003), and Neisseria meningitides (Sun et al. 2000).

Furthermore, certain metabolic intermediates have recently been implicated in important and varied roles in pathogenesis with respect to aggressiveness or cell-to-cell signaling in host tissues. These results indicated that before bacterial metabolic pathways within their host were fully understood, the roles of housekeeping genes remain difficult to explain. For example, hostderived lipoic acid was found to be critical for the growth and virulence of the intracytosolic pathogen Listeria monocytogenes (O'Riordan et al. 2003); a cluster of sulfur metabolism genes (e.g., $\operatorname{raxR}, \operatorname{rax} Q)$ are required for plant resistance gene $\mathrm{Xa21}$-mediated host recognition against $X$. oryzae pv. oryzae, the causative agent of rice bacterial blight (Burdman et al. 2004). In the present study, aromatic amino-acid biosynthesis genes, e.g., $\operatorname{trpD}, \operatorname{trpE}$, and $\operatorname{aroA}$ were found to be associated with $X c c$ pathogenesis (Supplemental Table 3). These genes are involved in the biosynthesis of anthranilate, which is a down-stream product of the shikimate-chorismate pathway (AroA) and is synthesized by anthranilate synthase (TrpD, TrpE, two subunits). It is worth mentioning that anthranilate is the precursor of intercellular signal molecule 2-heptyl-3-hydroxy-4-quinolone, which is involved in quorum sensing in $P$. aeruginosa (Pesci et al. 1999).

\section{Conclusions}

In conclusion, we report the complete genome sequence of Xcc 8004 and our observations of the various kinds of genetic variation that exist between Xcc 8004 and Xcc ATCC 33913. Our findings indicate that strain-specific genes, focused on genomic rearrangement-associated strain-specific segments, are likely to be the major driving force for strain differentiation. Furthermore, our high-throughput mutagenesis analysis method identified a wealth of genes that contribute to Xcc pathogenicity. These results provide new insight into the relationship between host specificity and Xcc genome evolution. Moreover, this work generated a mutant profile as a starting point from which to investigate the molecular pathogenesis of black rot disease.

\section{Methods}

\section{Genome sequencing and annotation}

Genomic DNA was sheared by sonication. The blunt-ends were created by mung bean nuclease, and 1.5-3.0 kb fragments were cloned into pUC18 digested with SmaI. The 8-10-kb inserts generated by Sau3AI/MboI were ligated into pUC18 digested with BamHI. Approximately 55,000 clones were sequenced from both ends on ABI3700 or MegaBACE DNA autosequencers. Sequence assembly was accomplished by Phred/Phrap/Consed. A total of 107,860 sequences (10-fold genome coverage) served as scaffolding, and gaps were filled by primer walking, subcloning, or multiplex PCR. The sequence assembly was confirmed by pulsed-field gel electrophoresis and Southern blotting analysis with PacI and PmeI. Putative CDSs were identified with GLIMMER. CDS functions were predicted by searching the database with BLAST, FASTA, and Pfam. Metabolic pathways were examined on KEGG. Transfer RNAs were predicted by TRNASCAN-SE.

\section{SNP analysis}

SNPs between the two Xcc genomes were identified by BLASTN $\left(e<10^{-5}\right)$. Synonymous and nonsynonymous sites were deter- mined by ClustalW. The number of nonsynonymous SNPs (A), synonymous SNPs (S), the value of average $\mathrm{SNP} /$ codon (ratio of total SNPs vs. total number of codons), and the ratios of total nonsynonymous SNPs vs. total synonymous SNPs (A/S) were calculated. $\mathrm{A} / \mathrm{S}$ differences among the gene groups were detected by $\chi^{2}$ tests.

\section{Mutant library construction and plant inoculation}

The large-scale transposon-insertional mutant library used in this study was constructed as described previously (Sun et al. 2003). The library contains 16,512 clones and was generated by transforming the EZ::TN $<\mathrm{KAN}-2>\mathrm{Tnp}$ transposome (Epicentre) into Xcc electro-competent cells. The saturation of this library was deduced as $97 \%$ (or $4 \times$ genome coverage) by its randomicity as determined by Southern blotting and flanking sequence analysis (Sun et al. 2003).

For plant inoculation, transformants were grown in PSA medium (peptone $10 \mathrm{~g} / \mathrm{L}$, sucrose $10 \mathrm{~g} / \mathrm{L}$, glutamic acid $1 \mathrm{~g} / \mathrm{L}$ ) with kanamycin $(25 \mu \mathrm{g} / \mathrm{mL})$ at $28^{\circ} \mathrm{C}$, shaking at $200 \mathrm{rpm}$ until the $\mathrm{OD}_{600}$ value reached $0.3-0.5$. Four-week-old cabbages (B. oleracae cultivar Jingfeng 1) were inoculated by clipping leaf tips with sterile scissors dipped in bacteria cultures. After inoculation, the plants were kept in a greenhouse at $28 \sim 35^{\circ} \mathrm{C}$, with a relative humidity $>95 \%$. Lesion length was scored $10 \mathrm{~d}$ after inoculation, and virulence level was scored as follows: 0 , no visible effect; 1 , limited chlorosis around the cut site; 2 , chlorosis extending from the cut site; 3 , blackened leaf veins, death, and drying of tissue within the chlorotic area; 4, extensive vein blackening, death, and drying of tissue (Dow et al. 1990). In the initial round of screening, the virulence level of transformants (a total of 16,512) was determined individually from a minimum of 12 innoculation sites distributed over at least three leaves on a minimum of two different plant individuals. Only transformants with significant decrease in virulence were selected as pathogenicity-deficient candidates and were confirmed further in at least four independent rounds of inoculation (at lease 24 innoculation sites for each transformant distributed over at least three leaves on a minimum of four different plant individuals). For host range determination, the confirmed pathogenicity-deficient mutants were inoculated onto different host plants, including two radish cultivars ( $R$. sativus $\mathrm{cv}$. Huaye and $R$. sativus $\mathrm{cv}$. Xiaojingzhong), Chinese cabbage (B. chinensis cv. Zhongbai 5) and pakchoi (B. chinensis cv. Wuyueman; all of these cultivars are available from the Institute of Vegetables and Flowers, Chinese Academy of Agricultural Sciences, Beijing 100081). Wild-type strains of Xcc 8004, Xcc ATCC 33913, and sterile water were used as controls.

\section{EZ::TN transposon copy number determination}

Genomic DNA of Xcc was extracted from Xcc and digested with PstI, which has no target site on the probe, but has one site at the 3' extreme end of EZ::TN transposon. The kanamycin resistance gene of the EZ::TN transposon was amplified with primers Kan-1 and Kan-2 (Supplemental Table 4) and labeled with $\left[\alpha^{32} \mathrm{P}\right] \mathrm{dCTP}$ by using the Prime-a-Gene labeling system (Promega).

\section{Flanking sequence analysis}

Genomic sequences flanking the EZ::TN transposon in mutants with reduced pathogenicity were analyzed using thermal asymmetric interlaced polymerase chains reactions (TĀIL-PCR) with three nested sequence-specific (SP) primers complementary to the transposon sequence and one arbitrary degenerate (AD) primer (Liu and Whittier 1995). The primer sequences are listed in Supplemental Table 4 and the TAIL-PCR procedure is summa- 
rized in Supplemental Table 5. TAIL-PCR products were cloned into the pGEM-T easy vector (Promega), sequenced, and mapped on the genome of Xcc 8004 .

\section{Acknowledgments}

We thank Professors X. Tang (Kansas State University), L Zhang (Institute of Molecular and Cell Biology, Singapore), R.L. Somerville (Purdue University), and C-I. Wu (Chicago University) for comments on the manuscript. Ms. Y.C. Fu helped to create the animated flash. This work was funded by the High-Tech Program (Grant 101-02-07-02) of Ministry of Science and Technology of China, the National Natural Science Foundation of China (Grants 30228002 and 30270027), and the Chinese Academy of Sciences (Grant KSCX2-SW-314 and "Bairen Jihua" to C.H.).

\section{References}

Alcantara, R.B., Read, R.D., Valderas, M.W., Brown, T.D., and Roop, R.M. 2004. Intact purine biosynthesis pathways are required for wild-type virulence of Brucella abortus 2308 in the BALB/c mouse model. Infect. Immun. 72: 4911-4917.

Alm, R.A., Ling, L.S., Moir, D.T., King, B.L., Brown, E.D., Doig, P.C., Smith, D.R., Noonan, B., Guild, B.C., deJonge, B.L., et al. 1999. Genomic-sequence comparison of two unrelated isolates of the human gastric pathogen Helicobacter pylori. Nature 397: 176-180.

Alvarez, A.M. 2000. Black rot of crucifers. In Mechanisms of resistance to plant diseases (eds. A.J. Slusarenko et al.), pp. 21-52. Kluwer Academic Publications, Dordrecht, Netherlands.

Bae, T., Banger, A.K., Wallace, A., Glass, E.M., Aslund, F., Schneewind, O., and Missiakas, D.M. 2004. Staphylococcus aureus virulence genes identified by bursa aurealis mutagenesis and nematode killing. Proc. Natl. Acad. Sci. 101: 12312-12317.

Becker, A., Katzen, F., Puhler, A., and Ielpi, L. 1998. Xanthan gum biosynthesis and application: A biochemical/genetic perspective. Appl. Microbiol. Biotechnol. 50: 145-152.

Bhattacharyya, A., Stilwagen, S., Ivanova, N., D'Souza, M., Bernal, A., Lykidis, A., Kapatral, V., Anderson, I., Larsen, N., Los, T., et al. 2002. Whole-genome comparative analysis of three phytopathogenic Xylella fastidiosa strains. Proc. Natl. Acad. Sci. 99: 12403-12408.

Burdman, S., Shen, Y., Lee, S.W., Xue, Q., and Ronald, P. 2004. RaxH/RaxR: A two-component regulatory system in Xanthomonas oryzae pv. oryzae required for AvrXa21 activity. Mol. Plant Microbe Interact. 17: 602-612.

Buttner, D. and Bonas, U. 2003. Common infection strategies of plant and animal pathogenic bacteria. Curr. Opin. Plant Biol. 6: 312-319.

Cascales, E. and Christie, P.J. 2003. The versatile bacterial type IV secretion systems. Nat. Rev. Microbiol. 1: 137-149.

Chan, J.W. and Goodwin, P.H. 1999. The molecular genetics of virulence of Xanthomonas campestris. Biotechnol. Adv. 17: 489-508.

Christie, P.J. and Vogel, J.P. 2000. Bacterial type IV secretion: Conjugation systems adapted to deliver effector molecules to host cells. Trends Microbiol. 8: 354-360.

Craig, L., Pique, M.E., and Tainer, J.A. 2004. Type IV pilus structure and bacterial pathogenicity. Nat. Rev. Microbiol. 2: 363-378.

da Silva, A.C., Ferro, J.A., Reinach, F.C., Farah, C.S., Furlan, L.R., Quaggio, R.B., Monteiro-Vitorello, C.B., Van Sluys, M.A., Almeida, N.F., Alves, L.M., et al. 2002. Comparison of the genomes of two Xanthomonas pathogens with differing host specificities. Nature 417: 459-463.

de Crecy-Lagard, V., Glaser, P., Lejeune, P., Sismeiro, O., Barber, C.E. Daniels, M.J., and Danchin, A. 1990. A Xanthomonas campestris pv. campestris protein similar to catabolite activation factor is involved in regulation of phytopathogenicity. I. Bacteriol. 172: 5877-5883.

Dow, J.M., Clarke, B.R., Milligan, D.E., Tang, J.L., and Daniels, M.J. 1990. Extracellular proteases from Xanthomonas campestris pv. campestris, the black rot pathogen. Appl. Environ. Microbiol. 56: 2994-2998.

Dow, J.M., Crossman, L., Findlay, K., He, Y.Q., Feng, J.X., and Tang, J.L. 2003. Biofilm dispersal in Xanthomonas campestris is controlled by cell-cell signaling and is required for full virulence to plants. Proc. Natl. Acad. Sci. 100: 10995-11000.

Dye, D., Bradbury, W., Goto, J.F., Hayward, M., Lelliott, A.C., and Schroth, M.N. 1980. International standards for naming pathovars of phytopathogenic bacteria and a list of pathovar names and pathotype strains. Rev. Plant Pathol. 59: 153-168.

Eisen, J.A., Heidelberg, J.F., White, O., and Salzberg, S.L. 2000. Evidence for symmetric chromosomal inversions around the replication origin in bacteria. Genome Biol. 1: research0011.

Feil, E.J. 2004. Small change: Keeping pace with microevolution. Nat. Rev. Microbiol. 2: 483-495.

Geoffroy, M.C., Floquet, S., Metais, A., Nassif, X., and Pelicic, V. 2003. Large-scale analysis of the meningococcus genome by gene disruption: Resistance to complement-mediated lysis. Genome Res. 13: 391-398.

Gray, Y.H. 2000. It takes two transposons to tango: Transposable-element-mediated chromosomal rearrangements. Trends Genet. 16: 461-468.

Holden, M.T., Feil, E.J., Lindsay, J.A., Peacock, S.J., Day, N.P., Enright, M.C., Foster, T.J., Moore, C.E., Hurst, L., Atkin, R., et al. 2004. Complete genomes of two clinical Staphylococcus aureus strains: Evidence for the rapid evolution of virulence and drug resistance. Proc. Natl. Acad. Sci. 101: 9786-9791.

Hughes, D. 2000. Evaluating genome dynamics: The constraints on rearrangements within bacterial genomes. Genome Biol. 1: reviews0006.

Israel, D.A., Salama, N., Krishna, U., Rieger, U.M., Atherton, J.C., Falkow, S., and Peek, R.M. 2001. Helicobacter pylori genetic diversity within the gastric niche of a single human host. Proc. Natl. Acad. Sci. 98: 14625-14630.

Kavermann, H., Burns, B.P., Angermuller, K., Odenbreit, S., Fischer, W., Melchers, K., and Haas, R. 2003. Identification and characterization of Helicobacter pylori genes essential for gastric colonization. J. Exp. Med. 197: 813-822.

Kozitskaya, S., Cho, S.H., Dietrich, K., Marre, R., Naber, K., and Ziebuhr, W. 2004. The bacterial insertion sequence element IS256 occurs preferentially in nosocomial Staphylococcus epidermidis isolates: Association with biofilm formation and resistance to aminoglycosides. Infect. Immun. 72: 1210-1215.

Kresse, A.U., Dinesh, S.D., Larbig, K., and Romling, U. 2003. Impact of large chromosomal inversions on the adaptation and evolution of Pseudomonas aeruginosa chronically colonizing cystic fibrosis lungs. Mol. Microbiol. 47: 145-158.

Kumar, M.J., Jamaluddin, M.S., Natarajan, K., Kaur, D., and Datta, A. 2000. The inducible N-acetylglucosamine catabolic pathway gene cluster in Candida albicans: Discrete N-acetylglucosamine-inducible factors interact at the promoter of NAG1. Proc. Natl. Acad. Sci. 97: 14218-14223.

Kurz, C.L., Chauvet, S., Andres, E., Aurouze, M., Vallet, I., Michel, G.P., Uh, M., Celli, J., Filloux, A., De Bentzmann, S., et al. 2003. Virulence factors of the human opportunistic pathogen Serratia marcescens identified by in vivo screening. EMBO J. 22: 1451-1460.

Leach, D.R., Okely, E.A., and Pinder, D.J. 1997. Repair by recombination of DNA containing a palindromic sequence. Mol. Microbiol. 26: 597-606.

Lerouge, I. and Vanderleyden, J. 2002. O-antigen structural variation: Mechanisms and possible roles in animal/plant-microbe interactions. FEMS Microbiol. Rev. 26: 17-47.

Lin, N.T., Wen, F.S., and Tseng, Y.H. 1996. A region of the filamentous phage $\phi L f$ genome that can support autonomous replication and miniphage production. Biochem. Biophys. Res. Commun. 218: 12-16.

Liu, Y.G. and Whittier, R.F. 1995. Thermal asymmetric interlaced PCR: Automatable amplification and sequencing of insert end fragments from P1 and YAC clones for chromosome walking. Genomics 25: $674-681$.

Mahan, M.J., Tobias, J.W., Slauch, J.M., Hanna, P.C., Collier, R.J., and Mekalanos, J.J. 1995. Antibiotic-based selection for bacterial genes that are specifically induced during infection of a host. Proc. Natl. Acad. Sci. 92: 669-673.

Matsunaga, I., Yokotani, N., Gotoh, O., Kusunose, E., Yamada, M., and Ichihara, K. 1997. Molecular cloning and expression of fatty acid $\alpha$-hydroxylase from Sphingomonas paucimobilis. J. Biol. Chem. 272: 23592-23596.

Mushegian, A.R. and Koonin, E.V. 1996. A minimal gene set for cellular life derived by comparison of complete bacterial genomes. Proc. Natl. Acad. Sci. 93: 10268-10273.

Nakagawa, I., Kurokawa, K., Yamashita, A., Nakata, M., Tomiyasu, Y . Okahashi, N., Kawabata, S., Yamazaki, K., Shiba, T., Yasunaga, T., et al. 2003. Genome sequence of an M3 strain of Streptococcus pyogenes reveals a large-scale genomic rearrangement in invasive strains and new insights into phage evolution. Genome Res. 13: 1042-1055.

Newman, M.A., von Roepenack-Lahaye, E., Parr, A., Daniels, M.J., and Dow, J.M. 2002. Prior exposure to lipopolysaccharide potentiates expression of plant defenses in response to bacteria. Plant J. 29: 487-495.

O’Riordan, M., Moors, M.A., and Portnoy, D.A. 2003. Listeria intracellular growth and virulence require host-derived lipoic acid.

\section{Genome Research}

www.genome.org 
Science 302: 462-464.

Parkhill, J., Sebaihia, M., Preston, A., Murphy, L.D., Thomson, N., Harris, D.E., Holden, M.T., Churcher, C.M., Bentley, S.D., Mungall, K.L., et al. 2003. Comparative analysis of the genome sequences of Bordetella pertussis, Bordetella parapertussis and Bordetella bronchiseptica. Nat. Genet. 35: 32-40.

Pesci, E.C., Milbank, J.B., Pearson, J.P., McKnight, S., Kende, A.S., Greenberg, E.P., and Iglewski, B.H. 1999. Quinolone signaling in the cell-to-cell communication system of Pseudomonas aeruginosa. Proc. Natl. Acad. Sci. 96: 11229-11234.

Shibata, Y., Yamashita, Y., Ozaki, K., Nakano, Y., and Koga, T. 2002. Expression and characterization of streptococcal rgp genes required for rhamnan synthesis in Escherichia coli. Infect. Immun. 70: 2891-2898.

Simpson, A.J., Reinach, F.C., Arruda, P., Abreu, F.A., Acencio, M., Alvarenga, R., Alves, L.M., Araya, J.E., Baia, G.S., Baptista, C.S., et al. 2000. The genome sequence of the plant pathogen Xylella fastidiosa. Nature 406: 151-157.

Slater, H., Alvarez-Morales, A., Barber, C.E., Daniels, M.J., and Dow, J.M. 2000. A two-component system involving an HD-GYP domain protein links cell-cell signalling to pathogenicity gene expression in Xanthomonas campestris. Mol. Microbiol. 38: 986-1003.

Smith, H. 1998. What happens to bacterial pathogens in vivo? Trends Microbiol. 6: 239-243.

Storch, K.F., Rudolph, J., and Oesterhelt, D. 1999. Car: A cytoplasmic sensor responsible for arginine chemotaxis in the archaeon Halobacterium salinarum. EMBO J. 18: 1146-1158.

Sun, Y.H., Bakshi, S., Chalmers, R., and Tang, C.M. 2000. Functional genomics of Neisseria meningitidis pathogenesis. Nat. Med. 6: 1269-1273.

Sun, Q., Wu, W., Qian, W., Hu, J., Fang, R., and He, C. 2003. High-quality mutant libraries of Xanthomonas oryzae pv. oryzae and $X$. campestris pv. campestris generated by an efficient transposon mutagenesis system. FEMS Microbiol. Lett. 226: 145-150.

Swings, J.G. and Civerolo, E.L. 1993. Xanthomonas. Chapman \& Hall, London.

Tang, J.L., Liu, Y.N., Barber, C.E., Dow, J.M., Wootton, J.C., and Daniels, M.J. 1991. Genetic and molecular analysis of a cluster of $r p f$ genes involved in positive regulation of synthesis of extracellular enzymes and polysaccharide in Xanthomonas campestris pathovar campestris. Mol. Gen. Genet. 226: 409-417.

Tillier, E.R. and Collins, R.A. 2000. Genome rearrangement by replication-directed translocation. Nat. Genet. 26: 195-197.

Van Sluys, M.A., Monteiro-Vitorello, C.B., Camargo, L.E., Menck, C.F., da Silva, A.C., Ferro, J.A., Oliveira, M.C., Setubal, J.C., Kitajima, J.P., and
Simpson, A.J. 2002. Comparative genomic analysis of plant-associated bacteria. Annu. Rev. Phytopathol. 40: 169-189.

Vorholter, F.J., Niehaus, K., and Puhler, A. 2001. Lipopolysaccharide biosynthesis in Xanthomonas campestris pv. campestris: A cluster of 15 genes is involved in the biosynthesis of the LPS O-antigen and the LPS core. Mol. Genet. Genomics 266: 79-95.

Vuilleumier, S. and Pagni, M. 2002. The elusive roles of bacterial glutathione S-transferases: New lessons from genomes. Appl. Microbiol. Biotechnol. 58: 138-146.

Walsh, N.P., Alba, B.M., Bose, B., Gross, C.A., and Sauer, R.T. 2003. OMP peptide signals initiate the envelope-stress response by activating DegS protease via relief of inhibition mediated by its PDZ domain. Cell 113: 61-71.

Wang, L.H., He, Y., Gao, Y., Wu, J.E., Dong, Y.H., He, C., Wang, S.X., Weng, L.X., Xu, J.L., Tay, L., et al. 2004. A bacterial cell-cell communication signal with cross-kingdom structural analogues. Mol. Microbiol. 51: 903-912.

Whittam, T.S. and Bumbaugh, A.C. 2002. Inferences from whole-genome sequences of bacterial pathogens. Curr. Opin. Genet. Dev. 12: 719-725.

Wilson, T.J., Bertrand, N., Tang, J.L., Feng, J.X., Pan, M.Q., Barber, C.E., Dow, J.M., and Daniels, M.J. 1998. The rpfA gene of Xanthomonas campestris pathovar campestris, which is involved in the regulation of pathogenicity factor production, encodes an aconitase. Mol. Microbiol. 28: 961-970.

Winzeler, E.A., Shoemaker, D.D., Astromoff, A., Liang, H., Anderson, K., Andre, B., Bangham, R., Benito, R., Boeke, J.D., Bussey, H., et al. 1999. Functional characterization of the $S$. cerevisiae genome by gene deletion and parallel analysis. Science 285: 901-906.

Wolfgang, M.C., Kulasekara, B.R., Liang, X., Boyd, D., Wu, K., Yang, Q., Miyada, C.G., and Lory, S. 2003. Conservation of genome content and virulence determinants among clinical and environmental isolates of Pseudomonas aeruginosa. Proc. Natl. Acad. Sci. 100: $8484-8489$.

Wren, B.W. 2000. Microbial genome analysis: Insights into virulence, host adaptation and evolution. Nat. Rev. Genet. 1: 30-39.

Zhong, S., Khodursky, A., Dykhuizen, D.E., and Dean, A.M. 2004 Evolutionary genomics of ecological specialization. Proc. Natl. Acad. Sci. 101: 11719-11724.

Received October 26, 2004; accepted in revised form April 15, 2005. 


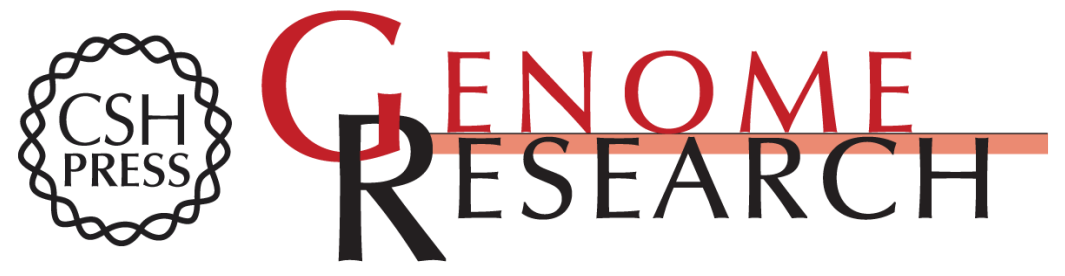

\section{Comparative and functional genomic analyses of the pathogenicity of phytopathogen Xanthomonas campestris pv. campestris}

Wei Qian, Yantao Jia, Shuang-Xi Ren, et al.

Genome Res. 2005 15: 757-767

Access the most recent version at doi:10.1101/gr.3378705

Supplemental Material

References

License

Email Alerting Service
http://genome.cshlp.org/content/suppl/2005/05/17/gr.3378705.DC1

This article cites 58 articles, 22 of which can be accessed free at: http://genome.cshlp.org/content/15/6/757.full.html\#ref-list-1

Receive free email alerts when new articles cite this article - sign up in the box at the top right corner of the article or click here.

\section{Affordable, Accurate Sequencing.}

